REVI EWS

\title{
Health policies in transition economics
}

\author{
Sushma Rudraswamy ${ }^{1}$, Nagabhushana Doggalli ${ }^{2}$ \\ 1. Department of Public Health Dentistry, JSS Dental College \& Hospital, JSS University, Mysore, Karnataka, India. \\ 2. Department of Oral Medicine and Radiology, JSS Dental College and Hospital, J SS University, Mysore, Karnataka, India \\ Correspondence: Sushma Rudraswamy. Address: Department of Public Health Dentistry, JSS Dental College \& Hospital, \\ JSS University, Mysore, Karnataka, India. Telephone: 08-212-548-351 Ext -8. Fax: 08-212-548-352. \\ E-mail: hisushhere@yahoo.co.in
}

Received: May 14, 2012

DOI : $10.5430 /$ jha.v1n1p42
Accepted: August 1, 2012

Published: September 1, 2012

\section{Abstract}

Historical evidence indicates that economic transformation, even with access and growth, can translate into social insecurities and health problems. The issue here is not whether transition economics should continue their reform process or not, since this has been historically proven necessary for the development of a country. Rather, it is about what the government can do to alleviate health problems through the adoption and implementation of sound policies. Since the health of a nation is strongly dependent on social, economic, and political stability sound health policies have to go hand in hand with adequate economic policies and a set of measures to ensure a social safety net to protect the relatively deprived.

Better health for the population should be the ultimate goal of health policies. Reforming health services and finance is just a means towards that end.

\section{Key words}

Health economics, Transition economics, Health policy, Health care reform

\section{Introduction}

Transition economy is used to refer to a country which is transformed from a predominantly state-owned centrally planned economy into a system with a free-market orientation and significant private ownership. Free market economy or a free enterprise economy is an economic system in which production and distribution of goods and services takes place through mechanism of free markets guided by free price system. In market economy businesses and consumers decide of their own volition what they will purchase and produce. Technically, this means that the producer gets to decide what to produce, how much to produce, what to charge to customers for those goods, what to pay employees and not the government ${ }^{[1]}$.

These decisions in the free market economy are influenced by

- Pressures of competition

- $\quad$ Supply

- Demand 
This is often contrasted with planned economy in which central government decides what will be produced and in what quantities. Transition economies undergo economic liberalization that is letting market forces set prices and lowering trade barriers. Macroeconomic stabilization where immediate high inflation is brought under control, and restructuring and privatization in order to create a financial sector and move from public to private ownership of resources.

Transition process is usually characterized by particularly private enterprises.

- The changing and creating of institutions

- Changes in the role of the state

- Promotion of private-owned enterprises, markets and independent financial institutions

- Increased inequality of incomes and wealth

- Dramatic increase in inflation

- Fall of Gross domestic product (GDP)

Gross domestic product (GDP) is the market value of all officially recognized final goods and services produced within a country in a given period. GDP per capita is often considered an indicator of a country's standard of living; under economic theory, GDP per capita exactly equals the gross domestic income (GDI) per capita. It is not to be confused with Gross National Product (GNP) which allocates production based on ownership. Gross domestic product is related to national accounts, a subject in macroeconomics.

Transition in a broad sense implies:

1. Liberalizing economic activity prices market operations, along with reallocating resources to their most efficient use.

2. Developing indirect, market-oriented instruments for macroeconomic stabilization;

3. Privatization achieving effective enterprise management and economic efficiency, usually through imposing hard budget constraints, which provides incentives to improve efficiency.

The existence of private property rights may be the most basic element of a market economy and therefore implementation of these rights is the main indication of transition process.

The overall transition indicators are:

- $\quad$ Large-scale privatisation

- $\quad$ Small-scale privatisation

- $\quad$ Governance and enterprise restructuring

- $\quad$ Price liberalisation

- $\quad$ Trade and foreign exchange system

- $\quad$ Competition policy

- $\quad$ Banking reform and interest rate liberalisation

- $\quad$ Securities markets and non-bank financial institutions

- Infrastructure reform 
According to the World Bank's "10 Years of Transition" report” the wide dispersion in the productivity of labour and capital across types of enterprises at the onset of transition and the erosion of those differences between old and new sectors during the reform provide a natural definition of the end of transition” ${ }^{[2]}$.

According to this..... Eight countries, (Czech Republic, Estonia, Hungary, Latvia, Lithuania, Poland, Slovakia, and Slovenia) have completed the transition process.

This review looks at the experience of transition from centrally planned to a market economy; it provides an overview of the current state of health systems in transition economies and examines their health strategies. And also encourages further discussion among policy makers and think tanks in the transition countries and will assist their dialogue with external donors and advisers on how to better support the transition process.

\section{Health in transition economies and health transition}

There should be a clarification of two concepts: health in transition and health policies in transition economies. The first term refers to the health situation during the transition process of former centrally planned transition economies which in many cases means an acute crisis with a , worsening of many health indicators. Conversely, the second term describes complex long-term changes in the health and disease patterns of specific populations. These changes are usually closely related to major economic, social, and demographic transformation of societies ${ }^{[3]}$.

\section{Why do health policies in transition economies deserve a separate discussion?}

Firstly, the transition has opened up both enormous opportunities and challenges and in the long run, a free-market economy is expected to result in improvements in living standards and, ultimately, the health of the people through higher income growth and the provision of more resources for human welfare. Historically income growth has been one of the most important factors, which explains the rise in life expectancy of a nation. However, in the short term, transformations often led to profound social, economic, and, in many countries, political upheavals that affected the welfare and health of many of its citizens. In this context, health strategies can help to ease or exacerbate the health problems of the transitional period.

Secondly, sharing similar legacies of the previous health systems, transition economies are embarking on a health-care reform process by adopting policies that bear much resemblance in nature. During this reform process, these countries are also facing many common obstacles.

Many transition economics have in common emerging health challenges brought about by an ageing population and an increasing burden of noncommunicable diseases, which is mostly attributable to tobacco and alcohol use, injuries, and traffic accidents. All of these are taking place in the face of a continued burden of communicable diseases.

\section{Possible explanations for the health crisis in transition economies}

There has been a debate on the key determinants of recent changes in the health status many possible explanations have been examined such as:

- Break-up of the health system and deterioration of health-care services

- Poor nutrition 
- Pollution

- Increasing income disparities within transition economies

- Psychological stress arising from economic and social instability and stress-related behavior such as tobacco and alcohol abuse

Researchers suggest that impoverishment is not a sufficient explanation. Obviously, it is not sufficient to depend solely on economic performance to bring about a health outcome. They also argue that contributions from the breakdown in health services, nutrition, and pollution are likely to be modest. Rather, much of the deterioration can be attributed to the impact of social and economic transition, exacerbated by a lack of social cohesion.

\section{The former health-care systems in transition economies}

Discussion of current health policies in transition economies is not complete without an examination of what they have inherited from the pre-existing health systems. Such a historical examination can provide explanations for the strengths and weaknesses of the current systems as well as a rationale for new health policies adopted by the governments.

Former health systems were characterized by a strong commitment of the state to the health of the people. Firstly before the transition, most countries had the model of free medical services for all, and this principle of universal access and equity was successful to some extent. Secondly, the states developed comparatively well-organized health-care systems with a strong emphasis on prevention. Thirdly, there was a build-up of a more extensive health-care infrastructure per capita in transition economies than in other countries at the same level of development. Thus, there exist comprehensive networks of health-care institutions and adequate numbers of staff in most transition economies as the legacy of past policies ${ }^{[4]}$. Most transition economies now have higher ratios of doctors and hospital beds per population than the averages for their corresponding income group.

Besides the advantages mentioned above, the former health systems in transition economies suffered from a number of short-comings. They were poorly maintained, with outdated management mechanisms. Years of rigid central planning and bureaucracy had led to limited efficiency and quality of the services and therefore the health systems were not operating to their full potential. Central planning, which placed great emphasis on meeting numerical targets and input indicators at the expense of quality and outputs, resulted in low-quality unbalanced physical infrastructure and staff in health care. For example, while many hospitals were constructed, investment in hospital equipment or other types of health facilities was neglected. Health professionals might have been abundant in numbers, yet many of them had low skills ${ }^{[5]}$.

In the former systems, the structure of primary care was specialist led, with patients either having direct access to specialists or being referred to the latter without receiving much care from general practitioners. Thus, general practice was neglected. Moreover, doctors were underpaid and became a socially and economically underprivileged group. As state employees, health professionals were paid irrespective of their efficiency and quality. Meanwhile, doctors, often without formal training in health management and administration, were running the system with an authoritarian management style. Many qualified health personnel became disillusioned with the system and started leaving the profession.

With regard to financing mechanisms, the old system relied on an inadequate state budget and a tightly centralized financial management structure in which the allocation of funds did not reflect local needs. For the above reasons, the old health systems failed to use resources to maximize gains in health outcomes and left negative impacts on the current systems. Coupled with the fiscal crisis, health systems in transition economies are struggling to cope with the current demand, especially with the extra burden exerted by the deterioration of health during the transition. 


\section{Policies to reform health-care systems in transition economies}

As part of a major social restructuring, many transition economies have had to overhaul their health systems amid a health crisis associated with the transition as well as the pre-existing problems of the inherited health-care legacy. Just like the move towards democracy, the process of health reform, which has great social arid economic implications, has not come without pain. The implementation of new health policies has resulted in a mixed record of both improvements and setbacks. One of the most difficult tasks is to reorganize health care and make it more cost-effective while ensuring its accessibility to those who need it most. Whether this can be done within the tight fiscal constraints in place during the transition to a market economy remains a great challenge. There appears to be conflict between long-term reform agendas and the short-term consequences that they brought about ${ }^{[6]}$.

This section focuses on the key components of the health system in which transition economies are facing great challenges and important policies that have recently been implemented in response. They include policies to reform financing mechanisms, introduce privatization into health care, and overhaul the management structures ${ }^{[7]}$.

- Policies to reform the financing mechanisms of public health

- Policies to create additional funding,

- Reduce the range of services,

- Scale down the massive infrastructure of the health sector,

- Introduction of varying degrees of private funding instruments, medical insurance, direct user charges and decentralization of health finance

\section{I mplementation, results and challenges}

The extent of success in implementing policies to reform health services varies among transition countries.

1. Data mostly available for the public sector indicate little significant restructuring of the public sectors health networks in most transitional economies.

2. Currently, there are not enough data to assess the impact of new policies on the improvement of quality and efficiency of care except in a few cases.

3. Privatization development has been rapid in the pharmaceutical and dentistry areas, slow in ambulatory care, and negligible for hospital care.

4. There have been many discussions on scaling down the massive infrastructure of the health-care system with such measures as reducing staff and closing hospitals. However, political constraints often prevent the successful implementation of such policies, except in Central and Eastern Europe where some success have been reported with decreases in number of hospital beds and average hospital stay.

5. The major challenges facing most transition economies include the following ${ }^{[8]}$ :

- Disparity in access to health services between the rich and the poor, the rural and the urban;

- Temporary market failure in the supply of heath care and drugs through weaknesses in regulations; 
- Resistance to the shift towards general practice from both the public, who are used to bypassing general practitioners, and the specialists, who feel that their jobs .are threatened by the changes;

- Regulation and quality control of both public and private services.

Despite recent reforms, health systems in many transitional economies remain predominantly publicly funded. Health expenditure as a percentage of gross domestic products in transition economies was higher than in developing countries at similar income levels 3 main challenges in the implementation of social insurance...

- Revenue obtained from insurance has been lower and less stable than expected.

- Mechanism to pay health-care providers is another issue to tackle.

- There is need to determine the right benefit package offered by the insurance scheme in terms of the items included and excluded from that package.

Adoption of payroll-based health insurance during the transition has been followed by a marked increase in health expenditure as a percentage of gross domestic products. This necessitates increased efficiency in public sector resource mobilization, explicit shift in Cost burden to the active population, and complete introduction of financial incentives in the implementation of social insurance. It is critical that health insurance schemes should he made as effective as possible and based on sound economic and actuarial principles ${ }^{[9,10]}$. The design of new health finance mechanisms should provide effective protection to vulnerable groups while, at the same time, encouraging the development of competition among providers. This requires a number of measures to increase revenue and make health expenditures more cost-effective.

With a new emphasis on cost recovery, health services now tend be available to those with the ability to pay. There have been concern and evidence that private payment for health care, especially at the point of delivery may be a barrier to access for the poor and reduce the utilization of health services. Analysis of a household survey in Kyrgyzstan showed that, in 1996, a quarter of those who were either sick or injured did not seek medical care because they could not afford. In Vietnam, outpatient consultation had declined by 50 per cent since the late 1980s, from 2.1 visits per capita in 19870.9 in 1993. For this reason, necessary government interventions are needed to provide health care for the indigent and public health services.

China offers interesting lessons for reform in health-care financing. It introduced social insurance reforms in the mid-1980s. With the new policies, a health-care utilization rate for both urban and rural populations was significantly increased from the mid-1980s to the early 1990s. The challenges are finance and provide both public health and health-care services to the poor in the countryside, where 70 per cent of the population reside ${ }^{[11]}$.

\subsection{Policies to reform health services}

There is an urgent need to improve the quantity, quality, and mix of health services in transition economies while making them more efficient and equitable.

Most transition economies are adopting similar policies enabling their health-care systems to depart from the model in which the state is the sole provider of health services, as well as making them more efficient, competitive, and decentralized

\subsection{Privatization of the health sector}

Most transition economies have adopted legislation to legalize the involvement of the private sector in the production, trade, and distribution of drugs, medical equipment, and supplies by doing this, transition economy have introduced market-oriented mechanisms into the health system, namely consumer choice and competition between different health-care providers. 


\subsection{Reform of management structures}

Is includes decentralization of health management, in which local health institutions are granted larger managerial autonomy and nearer ownership.

\subsection{Reform of human resources}

Financial incentives for health workers to improve quality and productivity are created by policies to introduce performance-based financial rewards. Reform efforts in medical education have been taken to introduce the concept of family practice and to train general practitioners.

\subsection{Promoting cost- effectiveness of the delivery system}

This is being accomplished by restructuring in favor of primary care, promoting general and family practice of medicine, and eliminating unnecessary hospital capacity and staff.

\subsection{Establishment of linked organizations}

One of the main features of the health system in a democratic society is the presence of organizations that serve as links between institutions and resources. These include associations of public health professionals, doctors, and other health-care workers, hospitals, health professional schools. Such organizations, once absent in the former health system, are now emerging in transition economies ${ }^{[12]}$.

\section{Conclusion}

Unfortunately, the public health function was neglected during the early phase of transition. Insurance and privatization-led health-care reform was higher on the political agenda and received more media and public attention in most transition economies. The transformation to the market-oriented finance mechanism has weakened the financing of public health function for two reasons. Firstly, as elsewhere in the world, there is competition between public health needs and individual health-care needs for funding, which became even more limited during the fiscal crisis. Secondly, in most transition economies, the general direction of health reform is towards decentralization of public sector services, privatization, recognition of patient choice, and introduction or increase of out-of-pocket expenses. Such application of market values to health care has created opportunities for improving the demand-focused health services.

\section{References}

[1] Frenk J.Financing as an instrument of public policy. Bull Pan Am Health Organ. 1988; 22(4): 440-6. PMid:3242742

[2] World Bank issues report about 10 years of transition to market economy [Internet]. Available from: www.mfa.gov.by/en/press/news_mfa/a6838c219938740f.html.

[3] Frenk J, Bobadilla JL, Sepulveda J. The health transition in Mexico: a proper model, Demos. 1988; 28-9. PMid:12158027

[4] Fidler A, Bredenkamp C, Schlippert S.Innovations in health services delivery from transition economies in Eastern Europe and Central Asia. Health Aff (Millwood). 2009; 28(4): 1011-21. PMid:19597200 http://dx.doi.org/10.1377/hlthaff.28.4.1011

[5] Ensor T, Informal payments for health care in transition economies. Soc Sci Med. 2004; 58(2): 237-46. http://dx.doi.org/10.1016/S0277-9536(03)00007-8

[6] Detels RS, Holland WW, McEwen JM, Omenn GS, Health policies, Oxford Textbook of Public Health, Oxford Medical Publications, 4th ed. 2007.

[7] Fischer, Stanley and Ratna Sahay (2000), “The Transition Economies after Ten Years,” IMF Working Paper No. WP0030 [Internet]. Available from: www.imf.org/external/pubind.htm.

[8] WHO Assessing Financing, Education, Management and Policy Context for Strategic Planning of Human Resources for Health 2007.

[9] Barbara Wejnert, Maternal Health Policies in Transition 1990-2006 Marriage and Family Review. 2008; 3: 180-209.

[10] Gao J, Qian J, E Health equity in transition from planned to market economy in China. Health Policy Plan. 2002 ; 17 Suppl: $20-9$. PMid:12477738 http://dx.doi.org/10.1093/heapol/17.suppl_1.20

[11] WHO/Europe | European Observatory on Health Systems and Policies [Internet]. Available at http://www.observatory.dk/Healthcare in Transition.

[12] WHO -Health policy [Internet]. Available from: http://www.who.int/topics/health_policy/en/. 